\title{
COMPUTERIZED ROAD EXCAVATION PERMIT PROCESSING AND UTILITY MANAGEMENT IN HONG KONG
}

\author{
Xiang $\mathrm{Yu}^{*}$, Xueqing Zhang and Yashuai Li \\ Department of Civil and Environmental Engineering \\ Hong Kong University of Science and Technology \\ Kowloon, Hong Kong \\ (*Corresponding author: xyuac@ust.hk)
}




\title{
COMPUTERIZED ROAD EXCAVATION PERMIT PROCESSING AND UTILITY MANAGEMENT IN HONG KONG
}

\begin{abstract}
Hong Kong has a dense distribution of utility services laid under its road network. Utility undertakers frequently demand road openings to install new services and/or maintain existing ones. Road openings can cause troubles to the road network and negatively impact the public interest. Highways Department is responsible for managing road openings in Hong Kong under the Land (Miscellaneous Provisions) Ordinance. Highways Department has spent a lot of efforts to computerize excavation permit processing and utility management. The computerized system has gone through several generations and the current one is called the excavation permit management system (XPMS). On the one hand, the XPMS handles various excavation permit processing functions including permit application/approval/refusal/issuance/extension/termination, fees/costs, permit conditions, and permit period assessment; on the other hand, the XPMS accounts for some important utility management issues such as spatial check, coordination of multiple openings, traffic management, audit inspection, and defect liability. This paper discusses how the application, coordination, and other administrations of an excavation permit are eased by using the XPMS in Hong Kong. Background information such as the governing legal and regulatory framework, and Highways Department's administrative structure is introduced. The system architecture and advantages of the XPMS are presented. The work procedures and various functions of the XPMS are studied in detail.
\end{abstract}

\section{KEYWORDS}

Road opening, Excavation permit, Permit processing, Utility management, Computer system

\section{INTRODUCTION}

A huge amount of utility services are laid beneath the 2,040 km road network in Hong Kong (HK). On average, under each $\mathrm{km}$ of road there are $47 \mathrm{~km}$ of utility services, and the density can be much higher in urban areas. Road openings are frequently demanded by utility undertakers (UUs) to install new services and/or maintain existing ones. However, the opening works can cause troubling disruptions to the road network. Highways Department (HyD), as the road maintenance authority in HK, is hence responsible for collaborating with UUs to minimize disturbances of road openings to the public. Road openings in Hong Kong must comply with the Cap. 28 Land (Miscellaneous Provisions) Ordinance (LMPO) (Department of Justice, 1997). Under the LMPO, a UU has to obtain an excavation permit (XP) from HyD before commencing an opening in a public land maintained by HyD. The LMPO was amended in 2003, and the amendments also require government departments to obtain XPs for their excavation works. To computerize XP processing and utility management, HyD developed a utility management system (UMS) in 1997. In 2002, an Internet interface for the UMS (IIUMS) was put forward to facilitate XP application through the Internet. The UMS was further enhanced in 2004 when the amendments of the LMPO came into effect. The UMS and IIUMS were superseded by a new system, the excavation permit management system (XPMS), in 2009. The XPMS is better than the previous systems in terms of efficiency, transparency, and user friendliness.

This paper discusses the use of the XPMS for computerized XP processing and utility management in HK. Background information such as the governing legal and regulatory framework, and HyD's administrative structure is introduced first. Then, the system architecture and advantages of the XPMS are presented. Finally, the workflow of XP processing and utility management using the XPMS is stated in detail.

\section{LEGAL AND REGULATORY FRAMEWORK}


As a consensus from international practices in countries/regions such as Australia (VicRoads, 2008), China (Shanghai People's Congress, 1997), HK, Singapore (Land Transport Authority, 2008), and United Kingdom (Butcher, 2010; Highway Authorities and Utilities Committee, 2011), road openings are governed by a legal and regulatory framework, as the result of extensive consultations with various stakeholders, to help realize an efficient and safe road network through reducing the disruptions generated from excavation works. The LMPO is the primary ordinance for road openings in HK. The main requirements on excavation works under the LMPO and the HyD's guidelines (HyD, 1995) are:

1) $\underline{X P}$. A UU or a government department has to obtain an XP from HyD before undertaking an opening in a government unleased land. One who excavates without an XP is liable to a fine and to imprisonment. In the application for an XP, the applicant needs to provide detailed information with respect to the opening, such as the geographical area to be worked on, the utility service to be laid, the exact excavation works to be done, and the intended start and end dates of the opening. An XP allows the permittee to occupy a certain area to perform excavation works for a certain period. A so-called emergency XP allows the permittee to excavate for an emergency incident for a period of $\leq 7$ days. The extent of an $\mathrm{XP}$ is normally limited to works that fall within a circular area of $450 \mathrm{~m}$ diameter.

2) Fees/costs. An XP is issued, upon payment of prescribed fees. To recover administrative costs, HyD charges application, extension, and daily fees. In addition, to minimize the delay in the excavations, HyD charges an economic cost daily if the excavations cannot be completed on time without accepted reasons and thus an XP extension is required.

3) Permit conditions. To effectively control excavation works, some conditions such as the qualifications of operatives and supervisors, safety measures, required qualities of the excavation works, and avoidance of unnecessary delay or obstruction are stipulated in an XP for the permittee to comply with. The permittee may nominate a contractor as a "nominated permittee", subject to that the contractor consents to comply with some of the permit conditions (otherwise to be complied with by the permittee) and HyD approves the nomination. Failure to comply with the LMPO and the permit conditions can invite fines, or render the permittee, contractor, or both to prosecutions. As government departments cannot be prosecuted, a reporting mechanism has been included in the LMPO for cases concerning contraventions made by government departments.

4) Issuance, refusal, and termination of an XP. HyD may refuse to issue an XP or extend the valid period for an XP. HyD may also terminate an XP if there is some serious contravention of the permit conditions. A notice of the termination will be sent to the permittee (and the nominated permittee, if any).

5) Traffic management. The applicant for an XP is required to submit a temporary traffic management plan to Police Force (PF) and Transport Department (TD) for advice if the proposed opening involves excavations on an important route, would cause closure of any lane of a carriageway, involves a change of the traffic flow direction of a carriageway, or involves diverting the pedestrian traffic to a carriageway. In addition, if the road opening would affect some traffic aids (e.g., traffic signs and road markings), then the applicant needs to submit relevant record photos before and after the opening to TD.

6) Advance notice. For an XP that is about to commence, the permittee is required to submit an advance notification to $\mathrm{HyD} \leq 14$ and $\geq 2$ working days, before the intended commencement date.

7) Completion of an opening. After completion of excavation works, the permittee is required to adequately reinstate the affected land. The permittee has to report completion within 14 working days from the permit expiry date, if any of the following circumstances is encountered: the reinstatement will be carried out by a third party, the reinstatement will be carried out by HyD at the permittee's own cost, temporary installations will be removed at a certain time after the permit expiry date, or the reinstatement will involve traffic aids. In addition, in case of early completion of the opening, the permittee is also required to report completion immediately after the completion. The permittee is responsible for the repair of the land damaged by an infrastructure failure, and needs to take reasonable measures to maintain the utility infrastructure to a satisfactory standard.

HyD has established a standing committee comprising representatives from different stakeholders including UUs, contractors, PF, and TD to regularly discuss and resolve issues related to management of road openings in view of the requirements of the LMPO.

\section{ADMINISTRATIVE STRUCTURE}


To process XP applications, HyD has set up an XP processing team in each of the Urban and New Territories regional offices. Upon receiving an XP application, the inspector of works (IOW) examines the proposed opening, checks for possible conflicts with the restrictions, coordinates a group of road openings in vicinity, consults PF and TD with temporary traffic arrangements and working hours, assesses the permit period, and ensures that the fees have been paid. After satisfactorily completing the procedures, the processing team issues the XP that is associated with a set of permit conditions. An audit inspection team (AIT) has been established to audit the permittee and contractor for their compliances with the permit conditions while the excavations are in progress, and an enforcement team (ET) to carry out appropriate remedial actions. The AIT and ET are independent of the regional offices.

\section{SYSTEM ARCHITECTURE AND ADVANTAGES OF THE XPMS}

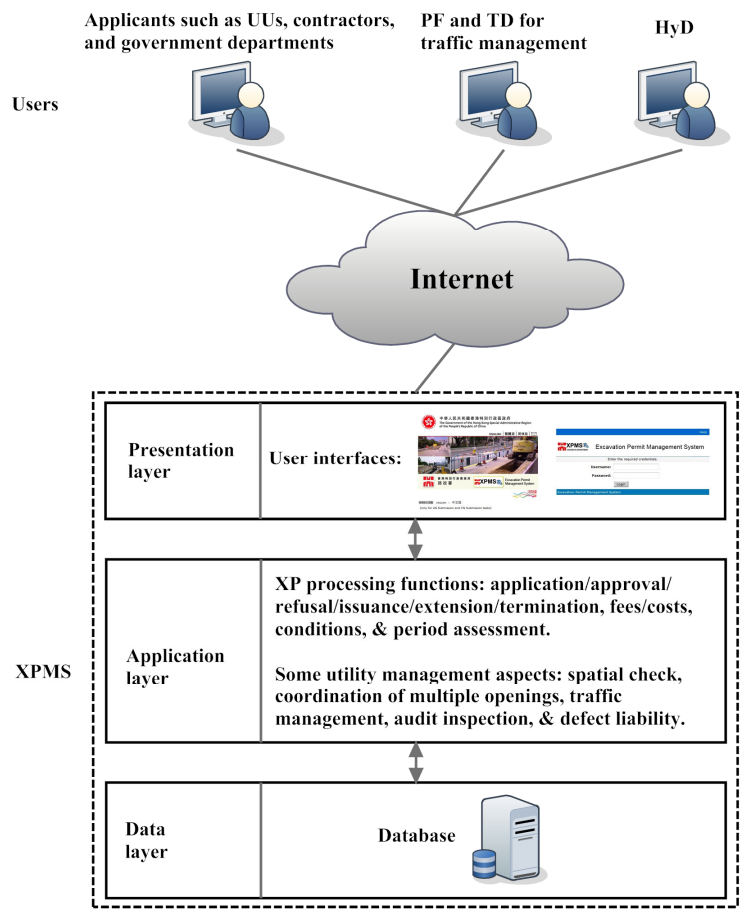

Figure 1 - System architecture of the XPMS

The Internet based 3-tier architecture of the XPMS (HyD, 2013a) is illustrated in Figure 1. Users of the XPMS are stakeholders in XP processing and utility management, including applicants, PF, TD, and HyD. Companies (such as UUs and contractors) and government departments need to contact HyD to register as users of the XPMS. The XPMS, not only handles various XP processing functions including permit application/approval/refusal/issuance/extension/termination, fees/costs, permit conditions, and permit period assessment, but also takes into account a number of important utility management aspects such as spatial check, coordination of multiple opening works, seeking traffic relevant advice from both PF and TD, audit inspection, and defect liability. The XPMS eases the application, coordination, and other administrations of an XP and outperforms its previous versions mainly in the following ways:

1) The UMS and IIUMS used two separate databases and two different digital map formats, thus the systems had to be shut down twice to synchronize data and a lot of conversions were required to update the map data, between the systems. The single database and the single map format used in the XPMS have eliminated the headaches.

2) The XPMS shortens the processing lead time by allowing the coordination of road openings in vicinity to proceed in parallel. 
3) In the XPMS, the start and end dates of the processes and the logical relationship among the processes can be easily traced, enabling better monitoring of the processing efficiency, and providing to users appropriate prompts and reminders.

4) The XPMS is more user-friendly, allowing users to conveniently track the application status and find their required information.

\section{COMPUTERIZED XP PROCESSING AND UTILITY MANAGEMENT}

The procedures for XP processing are compiled in an XP processing manual (HyD, 2013b) by HyD. As the workflow in Figure 2 shows, computerized XP processing and utility management using the XPMS covers the whole life cycle of a road opening, from the application of an XP to the reinstatement of the excavated land after completion of the excavations. Accordingly, there are four sequential phases: 1) registration; 2) assessment; 3) permit processing; and 4) work management.

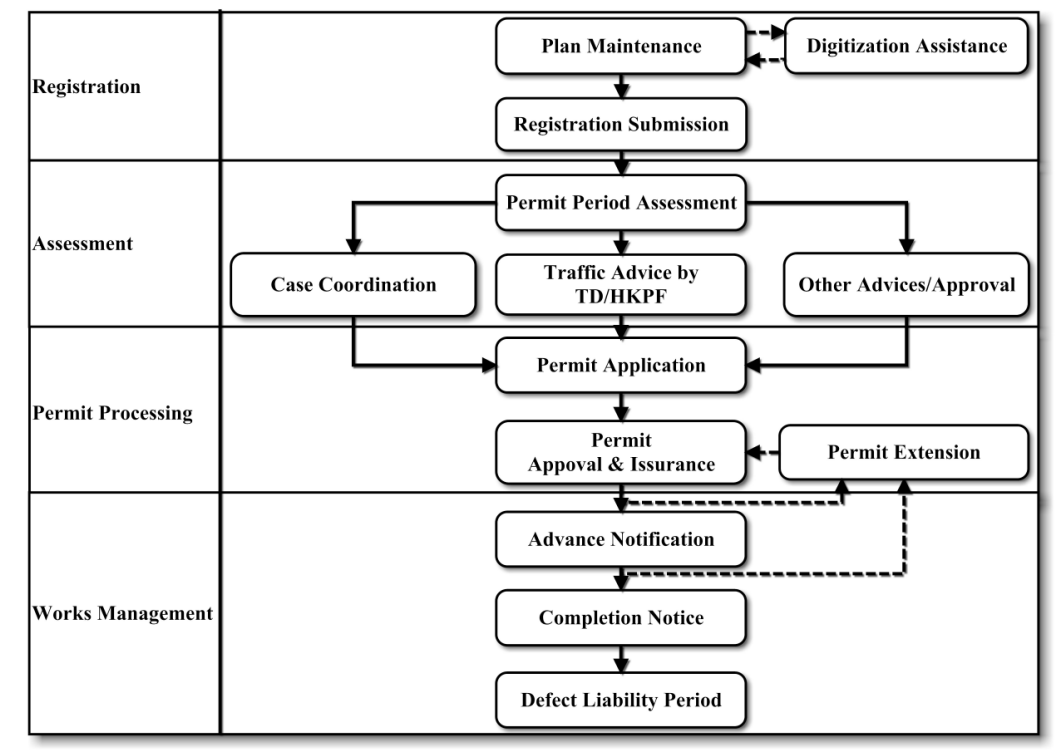

Figure 2 - Workflow of computerized XP processing and utility management using the XPMS

\section{Phase 1: Registration}

The applicant, including a UU or a government department, has to first register the proposed excavations in the XPMS by creating a plan. An applicant can apply for an XP for each plan. A plan is allowed to have more than one excavation item. Each item represents an excavation work on a carriageway, footway, verge, cycle track, or roadside slope maintained by HyD. The applicant is suggested not to group excavation items without intrinsic relations into a single plan.

The inputs of a plan include: 1) all mandatory textual information, such as the location and the proposed start date; 2) the alignment of the proposed excavations and the area with points/lines/polygons, based on which the XPMS determines the geographical extent that the excavations will cover; and 3) the program created by the Gantt chart in the XPMS.

To avoid the occurrence of any repeated opening at the location of the proposed plan, the XPMS performs a spatial check to find out whether any other permittee or the applicant has done excavations at that location recently before the intended start date, and any other permittee or the applicant will carry out excavations at that location soon after the intended end date. If a repeated opening is identified, the applicant needs to adjust the intended start date or apply for waiver(s) through the XPMS if the applicant 
considers that a violation cannot be avoided. The application for the waiver(s) is submitted to the IOW for vetting and then the responsible HyD officer for approval.

\section{Phase 2: Assessment}

When creating a new plan (other than for an emergency incident), the applicant needs to decide in which one of the following categories the plan falls: 1) a short duration plan $\leq 14$ working days; 2) a standard plan; or 3) a non-standard plan. For a standard plan, HyD has developed standard templates for permit period assessment according to the utility trade, road type, and length of the excavation works; whereas for a non-standard plan, the applicant is required to create a simple Gantt chart by completing a template as provided in the XPMS. Once the applicant has successfully registered the plan in the XPMS, the IOW will retrieve the plan details together with the permit period calculation, and assess the permit period calculated by the applicant. The IOW can either accept or amend with reasons the permit period proposed by the applicant. If necessary, the IOW may request the applicant to submit more information before accepting/amending the permit period. If not agreeing with the IOW's assessment, the applicant may appeal to higher level responsible HyD officers about the assessment.

Coordination of multiple conflicting plans aims to: 1) disallow a repeated opening; 2) disallow an unnecessary time gap between successive works; 3) encourage overlapping as far as possible; and 4) avoid an excessive total opening duration. The IOW checks whether the proposed plan is conflicting with any other plan in vicinity. If no conflict has been found, a new case is formed to contain the plan and the case status is set as "coordinated". If the IOW has found that the proposed plan is conflicting with other plan(s), the conflicting plan(s) are grouped into an "uncoordinated" case. For a newly formed uncoordinated case, the applicant of the plan with the earliest proposed start date will take the lead in coordinating with other applicants. Once all the concerned applicants agree with the coordinated program, they must immediately amend their plans to reflect the coordination and the lead applicant can then forward the case to HyD for acceptance. If one of the applicants fails to update or refuses to adjust the plan, the lead applicant may submit the program for acceptance and state the reasons for assessment.

For a plan that doesn't require a temporary traffic management proposal, the applicant has to submit a lighting, signing, and guarding proposal to PF. TD/PF will provide comments on the traffic related proposal. The applicant then revises the proposal according to the comments and resubmits it to $\mathrm{TD} / \mathrm{PF}$. When the revised proposal is agreed by TD/TF, the plan will enter the permit processing phase. Note that a traffic management liaison meeting is held among applicants, consultants, TD and PF for a large project ( 2 to 3 million HK dollars), and the consultations to the District Council and local residents/businesses are also critical for the successful application of an XP.

The status of a coordinated plan may be reverted to different stages due to various reasons. For example, if the plan's duration needs to be prolonged, the plan will be reverted to the permit period assessment stage; or when the plan's excavation alignment needs to be changed, the plan will be reverted to the plan registration stage.

\section{Phase 3: Permit Processing}

After the plan is coordinated and the traffic relevant proposal is accepted, the applicant proceeds to apply for an XP. Application for an XP has to be submitted $>5$ working days before the road opening commences. Up receipt of an XP application, the IOW checks whether the proposed excavations have any potential conflict with other planned/existing works and there is any special event that would affect the proposed excavations, and then recommend the responsible Engineer/Chief Technical Officer (E/CTO) to accept the application with suitable permit conditions and/or suggest the applicant to revise the proposed start date. The E/CTO may refuse to issue an XP if it is reasonably believed that the applicant cannot comply with the permit conditions (e.g. public nuisance eliminations and fire/traffic safety), the applicant doesn't have sufficient financial resources to do the excavations, or the circumstances for the application are inappropriate (e.g. various land use restrictions). The applicant can apply for an extension of the valid 
permit period before the XP expires. The required information in the extension application includes: 1) an updated work program to include the extension period; 2) a reduced alignment representing the works to be done during the extension; and 3) an updated traffic related proposal if there is any change caused by the extension. Other permittees in the same coordinated case need to be notified when the extension application is initiated. The E/CTO can either accept or amend with reasons the proposed extension period. Normally, the E/CTO will approve the extension application except in some circumstances, e.g. the contractor has not diligently carried out the works, resulting in a slow progress and failure to complete the works within the permit period; in this case, the E/CTO will assess the time required to reinstate the excavated land and issue an XP extension if the remaining period is inadequate.

The permittee may nominate the contractor as a nominated permittee, with evidences to substantiate the nominee's competence in terms of technical and management experience and financial capability. The E/CTO assesses the nomination and notifies the permittee and nominee the assessment result, with reasons if the nomination is refused.

\section{Phase 4: Works Management}

Upon receipt of an advance notification, the AIT will carry out audit inspection(s) of the excavation site. Each day, the audit inspection results are published to allow the permittees to check for non-compliances identified and take immediate corrective actions. The AIT issues advisory letters to the permittees and nominees when the contraventions are to an extent inviting enforcement actions. The letters are referred to the ET at the same time. Upon receiving the referral, the ET will investigate and collect evidences about the contraventions. The evidences collected are used to decide whether any summons is to be made. If the contraventions are made by a government department, HyD will write to the department to ask for an investigation whether it is due to the negligence of a public officer.

HyD may terminate an XP if there is any breach of the permit conditions, especially when the offences endanger the public interest. HyD assess the site and decide whether a suspension is to be issued to the permittee. HyD will cancel the suspension if the permittee and nominee have satisfactorily adopted all necessary safety precautions and provided adequate structural stability supports to protect the public from any danger. If the permittee or nominee fails to rectify the imminently dangerous situation as advised by the AIT during a follow-up site audit, HyD may immediately terminate the XP.

HyD will arrange a reinstatement inspection soon after the permit expiry date or within 7 working days upon receipt of a completion notice. After the inspection, the IOW will inform the permittee whether he/she agrees that the works have been satisfactorily completed. If the IOW disagrees, he/she will inform the permittee about the item(s) that do not comply with the requirements and request the permittee to rectify. In case a defective reinstatement is identified, the permittee needs to initiate an XP to rectify the corresponding reinstatement area even if the completion notice might have already been approved.

In case of a subsidence of or a deterioration in the permanent reinstatement within one year from the submission date of the completion notice or permit expiry date (whichever is the earlier), the permittee needs to carry out necessary remedial works at own expense, unless the permittee can prove that the defect was caused by a third party. When necessary, HyD will carry out the remedial works and the permittee must pay all the expenses incurred.

\section{CONCLUSIONS}

This paper has presented how HK deals with XP processing and utility management using a computerized system called XPMS. The governing legal and regulatory framework, and HyD's administrative structure have been introduced. The system architecture, advantages, and workflow of the XPMS have been studied. The XPMS has comprehensively addressed various XP processing functions and utility management issues, and it has facilitated the processing and management through an Internet based architecture. This paper is able to help concerned government officials and researchers around the world to 
gain a basic understanding of computerized XP processing and utility management in a typical metropolis like HK.

\section{ACRONYMS}

Audit Inspection Team (AIT)

Enforcement Team (ET)

Engineer/Chief Technical Officer (E/CTO)

Excavation Permit (XP)

Excavation Permit Management System (XPMS)

Highways Department (HyD)

Hong Kong (HK)

Inspector of Works (IOW)

Land (Miscellaneous Provisions) Ordinance (LMPO)

Police Force (PF)

Transport Department (TD)

Utility Undertaker (UU)

\section{REFERENCES}

Butcher, L. (2010). Roads: Public Utilities and Street Works, House of Commons, London

Department of Justice (1997). Cap 28 Land (Miscellaneous Provisions) Ordinance. Retrieved from the Bilingual Laws Information System website: http://www.legislation.gov.hk

Highway Authorities and Utilities Committee (2001). Best Practice in Street Works and Highway Works, London, UK.

Highways Department (HyD) (1995). Guidance Notes/HyD Guidelines. Retrieved from the Highways Department website: http://www.hyd.gov.hk/eng/public/publications/guidance notes/.

Highways Department (HyD) (2013a). Excavation Permit Management System. Retrieved from the Excavation Permit Management System website: https://xpms.hyd.gov.hk/.

Highways Department (HyD) (2013b). Excavation Permit Processing Manual. Retrieved from the Highways Department website: http://www.hyd.gov.hk/eng/public/publications/xppm/manual/

Land Transport Authority (2008). Code of Practice for Works on Public Streets, Singapore.

Shanghai People's Congress (1997), Shanghai Urban Roads and Bridges Management Regulation, Shanghai People's Congress, Shanghai, China.

VicRoads (2008), Code of Practice for Management of Road and Utility Infrastructure in Road Reserves, State Government of Victoria, Melbourne, Australia. 